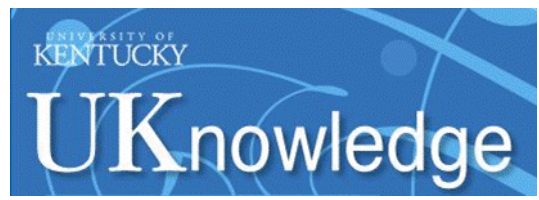

University of Kentucky

UKnowledge

\title{
Fault Identification and Location for Distribution Network with Distributed Generations
}

\author{
Wen Fan \\ University of Kentucky \\ Yuan Liao \\ University of Kentucky, yuan.liao@uky.edu
}

Follow this and additional works at: https://uknowledge.uky.edu/ece_facpub

Part of the Digital Communications and Networking Commons, and the Power and Energy Commons Right click to open a feedback form in a new tab to let us know how this document benefits you.

\section{Repository Citation}

Fan, Wen and Liao, Yuan, "Fault Identification and Location for Distribution Network with Distributed Generations" (2018). Electrical and Computer Engineering Faculty Publications. 22.

https://uknowledge.uky.edu/ece_facpub/22

This Article is brought to you for free and open access by the Electrical and Computer Engineering at UKnowledge. It has been accepted for inclusion in Electrical and Computer Engineering Faculty Publications by an authorized administrator of UKnowledge. For more information, please contact UKnowledge@lsv.uky.edu. 


\section{Fault Identification and Location for Distribution Network with Distributed Generations}

\section{Digital Object Identifier (DOI)}

https://doi.org/10.1515/ijeeps-2018-0048

\section{Notes/Citation Information}

Published in International Journal of Emerging Electric Power Systems, v. 19, issue 3, 20180048, p. 1-13.

(C) 2018 Walter de Gruyter GmbH, Berlin/Boston.

The copyright holder has granted the permission for posting the article here. 


\title{
Fault Identification and Location for Distribution Network with Distributed Generations
}

\author{
${ }^{1}$ University of Kentucky, ECE, 453 F Paul Anderson Tower, Lexington, KY, USA, E-mail: yliao@engr.uky.edu
}

\begin{abstract}
:
Power distribution networks with distributed generations may experience faults. It is essential to promptly locate the fault for fast repair and restoration. This paper presents a novel method for identifying the faulted section and accurate location of faults that occur on power distribution grid. Appropriate matrices are set up to represent meter locations on the grid and the topology of the grid. The voltage and current measurements obtained are utilized to decide the fault sections. Then fault location is determined by solving equations that link measurements and fault locations through bus impedance matrix. The method is applicable to both single and simultaneous, multiple faults that may occur on unbalanced, meshed distribution networks with distributed generations.
\end{abstract}

Keywords: distribution system, fault location, fault section identification, distributed generation

DOI: $10.1515 /$ ijeeps-2018-0048

Received: January 29, 2018; Revised: May 4, 2018; Accepted: May 14, 2018

\section{Introduction}

There is an increasing deployment of distributed renewable sources such as wind and solar generation in power distribution networks. These distributed generations (DG) will alter the common one direction power flow and complicate protection scheme. The output of DG is quite intermittent and uncertain. When faults occur on the network, it is pivotal to quickly locate the fault before any repair can be done. So, speedy and accurate fault location is key to fast system restoration following fault occurrence [1].

Various fault location methods for distribution system have been proposed in the past [1]. The authors of [2] design a single-ended fault location method by injecting a traveling wave into the circuit and applying the cross time-frequency reflectometry technique. An optimization method based on integer programming is proposed to determine the faulted line section in [3]. In [4], a method for identifying fault location by using voltage transient waveforms in distribution systems is presented. Reference [5] describes an integrated impedance and transient-based formulation for fault location in distribution systems. The authors in [6] discuss a method for identifying faulted segments on multi-phase distribution primaries using sequence component modeling and standard three-phase short-circuit solvers. Machine-learning is utilized in [7] to pinpoint fault location by using smart meters along the primary feeders. The author of [8] presents a fault location method for radial distribution networks. A discussion of fault location observability for distribution system is provided in [9]. In [10], algorithms for locating simultaneous faults are proposed by using measurements either from all sources or selected locations.

There is still a need for methods to deal with: unbalances of distribution system, presence of DG, modeling of shunt capacitances of feeders, occurrence of simultaneous multiple faults, and any type of faults. This paper aims to fill this gap and propose a graph based method for identifying faulted sections and fault location method for locating single or multiple faults.

The rest of the paper is organized as follows. Section 2 presents the fault section identification method. Section 3 describes the proposed fault location method. Evaluation studies are presented in Section 4, followed by conclusion.

\section{Proposed Method for Fault Section Identification}

In this section, a method for identifying the fault section by using voltage and current measurements recorded from meters placed across the system is developed. If only voltage measurements are available, then currents

Wen Fan is the corresponding author

(c) 2018 Walter de Gruyter $\mathrm{GmbH}$, Berlin/Boston. 
need to be estimated from voltage measurements. The derivation of line currents based on voltage measurements is presented in Section 2.1. If current measurements are available, they will be used directly for identifying the faulted sections.

\subsection{Derivation of Line Currents}

This section presents the developed module for obtaining the line currents in terms of voltage measurements and line impedances.

Figure 1 depicts the diagram of a three-phase line section. Buses $p$ and $q$ represent the two terminals of this line section. Bus $p$ comprises nodes $p_{1}, p_{2}$, and $p_{3}$. Bus $q$ includes nodes $q_{1}, q_{2}$, and $q_{3}$. The remaining notations are explained as follows:

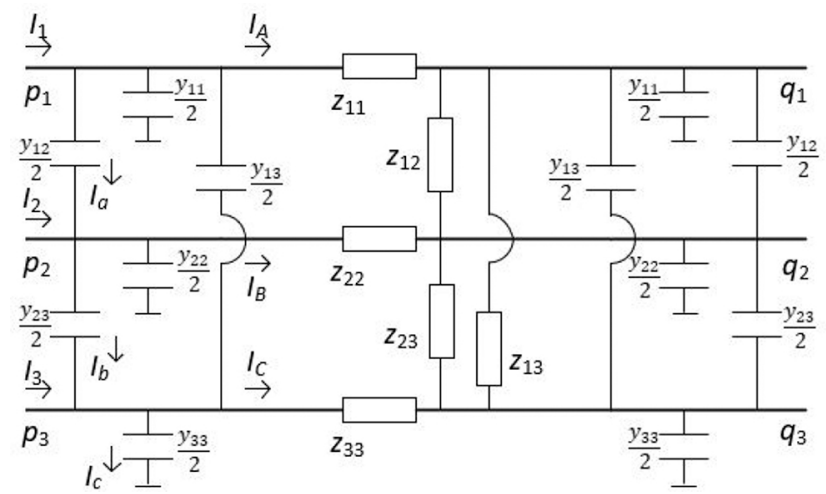

Figure 1: Section of a three-phase line.

$y_{11}, y_{22}, y_{33}$ : self-series admittance of the line;

$y_{12}, y_{13}, y_{23}$ : mutual series admittance of the line;

$z_{11}, z_{22}, z_{33}$ : self-series impedance of the line;

$z_{12}, z_{13}, z_{23}$ : mutual series impedance of the line;

$I_{1}, I_{2}, I_{3}$ : total line currents for phase A, B, and C;

$I_{a}, I_{b}, I_{c}$ : shunt currents for phase A, B, and C;

$I_{A}, I_{B}, I_{C}$ : line currents through series line impedance for phase $\mathrm{A}, \mathrm{B}$, and $\mathrm{C}$;

$V_{p_{1}}, V_{p_{p_{2}}}, V_{p_{3}}$ : voltage at node $p_{1}, p_{2}$, and $p_{3}$, respectively;

$V_{q_{1}}, V_{q_{2}}, V_{q_{3}}$ : voltage at node $q_{1}, q_{2}$, and $q_{3}$, respectively.

The shunt current that flows out from node $p_{1}$ is derived as

$$
I_{a}=\frac{y_{11}}{2} V_{p_{1}}+\frac{y_{12}}{2}\left(V_{p_{1}}-V_{p_{2}}\right)+\frac{y_{13}}{2}\left(V_{p_{1}}-V_{p_{3}}\right) .
$$

In a similar way to (1), shunt currents that flow out from node $p_{2}$, and $p_{3}$ can be written as

$$
\begin{aligned}
& I_{b}=\frac{y_{12}}{2}\left(V_{p_{2}}-V_{p_{1}}\right)+\frac{y_{22}}{2} V_{p_{2}}+\frac{y_{23}}{2}\left(V_{p_{2}}-V_{p_{3}}\right), \\
& I_{c}=\frac{y_{13}}{2}\left(V_{p_{3}}-V_{p_{1}}\right)+\frac{y_{23}}{2}\left(V_{p_{3}}-V_{p_{2}}\right)+\frac{y_{33}}{2} V_{p_{3}} .
\end{aligned}
$$

Equations (1) - (3) can be written in a compact format as follows:

$$
\left[\begin{array}{c}
I_{a} \\
I_{b} \\
I_{c}
\end{array}\right]=\frac{1}{2}\left[\begin{array}{ccc}
y_{11}+y_{12}+y_{13} & -y_{12} & -y_{13} \\
-y_{12} & y_{12}+y_{22}+y_{23} & -y_{23} \\
-y_{13} & -y_{23} & y_{13}+y_{23}+y_{33}
\end{array}\right]\left[\begin{array}{c}
V_{p_{1}} \\
V_{p_{2}} \\
V_{p_{3}}
\end{array}\right]
$$

Voltage at node $p_{1}$ can be derived as

$$
V_{p_{1}}=z_{11} I_{A}+z_{12} I_{B}+z_{13} I_{C}+V_{q_{1}}
$$


Similarly, voltage at node $p_{2}$ and $p_{3}$ can be expressed as

$$
\begin{aligned}
& V_{p_{2}}=z_{12} I_{A}+z_{22} I_{B}+z_{23} I_{C}+V_{q_{2}} \\
& V_{p_{3}}=z_{13} I_{A}+z_{23} I_{B}+z_{33} I_{C}+V_{q_{3}}
\end{aligned}
$$

Equations (5) - (7) can be written in a compact format as

$$
\left[\begin{array}{l}
V_{p_{1}} \\
V_{p_{2}} \\
V_{p_{3}}
\end{array}\right]=\left[\begin{array}{lll}
z_{11} & z_{12} & z_{13} \\
z_{12} & z_{22} & z_{23} \\
z_{13} & z_{23} & z_{33}
\end{array}\right]\left[\begin{array}{c}
I_{A} \\
I_{B} \\
I_{C}
\end{array}\right]+\left[\begin{array}{l}
V_{q_{1}} \\
V_{q_{2}} \\
V_{q_{3}}
\end{array}\right]
$$

Based on (8), line currents on phase A, B, and C can be acquired as

$$
\left[\begin{array}{c}
I_{A} \\
I_{B} \\
I_{C}
\end{array}\right]=\left[\begin{array}{lll}
z_{11} & z_{12} & z_{13} \\
z_{12} & z_{22} & z_{23} \\
z_{13} & z_{23} & z_{33}
\end{array}\right]^{-1}\left(\left[\begin{array}{c}
V_{p_{1}} \\
V_{p_{2}} \\
V_{p_{3}}
\end{array}\right]-\left[\begin{array}{l}
V_{q_{1}} \\
V_{q_{2}} \\
V_{q_{3}}
\end{array}\right]\right)
$$

The total line currents on phase A, B and C are given by

$$
\left[\begin{array}{l}
I_{1} \\
I_{2} \\
I_{3}
\end{array}\right]=\left[\begin{array}{l}
I_{a} \\
I_{b} \\
I_{c}
\end{array}\right]+\left[\begin{array}{l}
I_{A} \\
I_{B} \\
I_{C}
\end{array}\right]
$$

Substituting (4) and (9) into (10) results in

$$
\begin{aligned}
& {\left[\begin{array}{c}
I_{1} \\
I_{2} \\
I_{3}
\end{array}\right]=\left[\begin{array}{lll}
Z_{11} & Z_{12} & Z_{13} \\
Z_{12} & Z_{22} & Z_{23} \\
Z_{13} & Z_{23} & Z_{33}
\end{array}\right]^{-1}\left(\left[\begin{array}{c}
V_{p 1} \\
V_{p 2} \\
V_{p 3}
\end{array}\right]-\left[\begin{array}{c}
V_{q 1} \\
V_{q 2} \\
V_{p 3}
\end{array}\right]\right)} \\
& +\frac{1}{2}\left[\begin{array}{ccc}
y_{11}+y_{12}+y_{13} & -y_{12} & -y_{13} \\
-y_{12} & y_{12}+y_{22}+y_{23} & -y_{23} \\
-y_{13} & -y_{23} & y_{13}+y_{23}+y_{33}
\end{array}\right]\left[\begin{array}{c}
V_{p 1} \\
V_{p 2} \\
V_{p 3}
\end{array}\right]
\end{aligned}
$$

Equation (11) represents the total line current on each phase in terms of node voltages, shunt admittances, and line impedances. Consequently, if voltage measurements are known, line currents on corresponding line sections can be obtained, which will be used for fault section identification.

\subsection{Fault Section Identification}

This section presents the fault section identification algorithm based on current measurements or derived current values and graph theory.

The algorithm is based on two matrices, a current vector $I$ and a connection matrix $N$. The current vector I consists of currents flowing through the section boundaries. Note that the currents utilized are fundamental frequency phasors.

The network is represented as a directed graph consisting of nodes and arcs (i. e., branches). The connection matrix $N$ is defined based on the connection of sections through nodes and the reference current direction. Let $N_{k l}$ denote the $k t h$ row, and $l$ th column of $N$. Then matrix $N$ is formulated as follows:

1. For a system with $k$ branched sections and $l$ nodes, the dimension of the matrix $N$ is $k$ by $l$.

2. $N_{k l}=1$, if node $l$ has a reference current flowing into the $k$ th section.

3. $N_{k l}=-1$, if node $l$ has a reference current flowing out of the $k t h$ section.

4. $N_{k l}=0$, if node $l$ is not connected to the $k t h$ section. 
5. Repeat step (2) - (4) until all branch sections and nodes are included in the matrix $N$.

It is noted that the direction of reference current can be arbitrary.

Fault section identification vector is given by

$$
F_{S}=N I
$$

The magnitude of each element of $F_{S}$ indicates whether a fault occurs in the corresponding section or not.

In practice, $F_{S}$ will be calculated for phase $A, B$, and $C$, separately. Take phase A as an example,

$$
F_{S_{a}}=N I_{1}
$$

where $F_{S a}$ is the fault section identification vector for phase A. If the $k_{t h}$ row of $F_{S a}$ is much larger than the pre-fault value, then a fault involving phase A occurring in section $k$ is indicated.

It is evident that the resolution fault section identification depends on the number of meters placed on the grid. The more meters available, the more accurate the fault section identification will be. Ideally, if there will be meters placed at each end of every feeder, then the exact faulted section will be able to be systematically identified by the proposed method. In practical applications, network partition will depend on availability and location of meters.

It is noted that the fault section algorithm works for both single and multiple simultaneous faults for all fault types.

The fault section identification method is illustrated based on a 21-bus system, which is shown in Figure 2. The network will be divided into sections to demonstrate the algorithm developed. It is assumed that the currents at the boundaries of the sections are obtained by recording devices. These currents make up the current vector $I$.

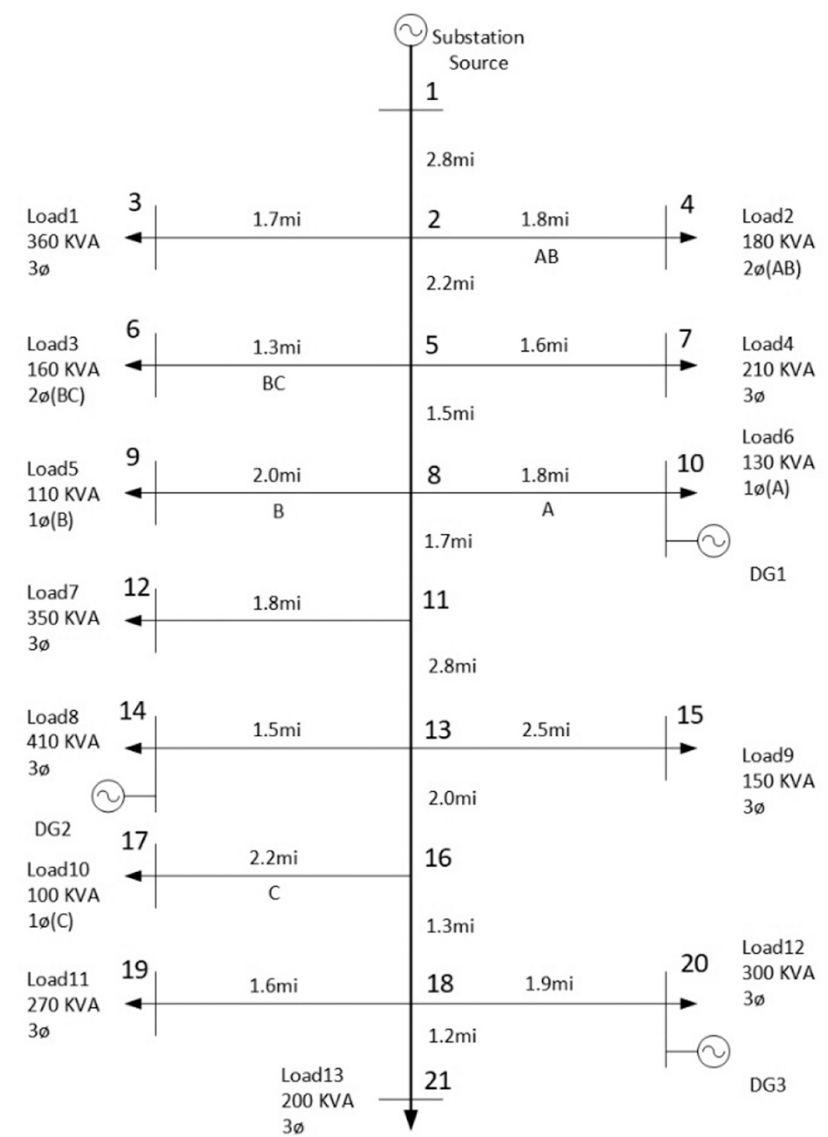

Figure 2: A 21-bus system used in study.

\subsubsection{Network Partition I}

This part presents the fault section identification algorithm for the network being partitioned into four sections. Figure 3 depicts the network partition, where the arrow symbol indicates the reference current direction, 
symbol $\mathrm{N}$ represents the switching and recording devices, and symbol $\mathrm{S}$ represents the sections. Provided that switching devices are available, the faulted sections once detected can be quickly isolated.

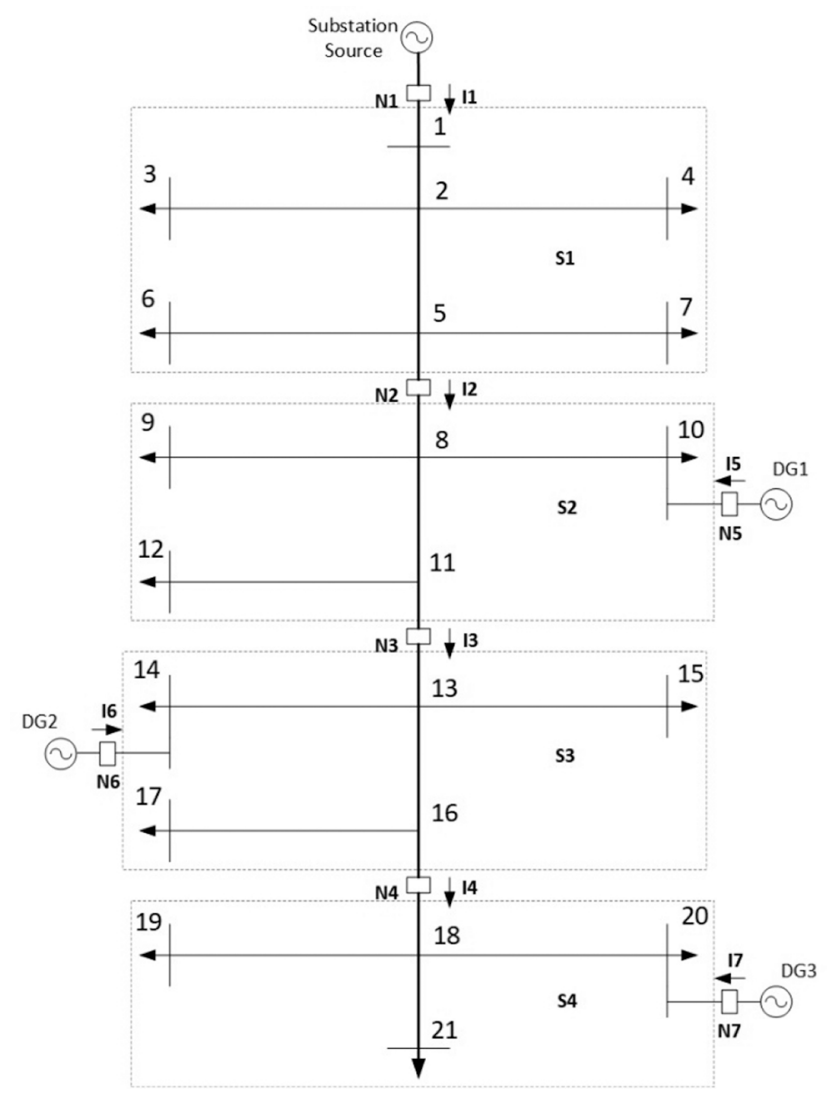

Figure 3: A 21-bus system being divided into four sections.

Equation (14) shows the connection matrix $N$ of the network

$$
N=\left[\begin{array}{ccccccc}
1 & -1 & 0 & 0 & 0 & 0 & 0 \\
0 & 1 & -1 & 0 & 1 & 0 & 0 \\
0 & 0 & 1 & -1 & 0 & 1 & 0 \\
0 & 0 & 0 & 1 & 0 & 0 & 1
\end{array}\right]
$$

The current vector $I$ consists of currents flowing through the section boundaries:

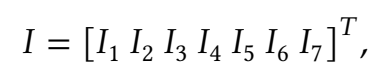

where subscript $T$ denotes transpose. The currents are labeled in Figure 3.

Substituting (14) and (15) into (12), fault section identification vector $F_{S}$ is obtained as

$$
F_{S}=\left[\begin{array}{c}
I_{1}-I_{2} \\
I_{2}-I_{3}+I_{5} \\
I_{3}-I_{4}+I_{6} \\
I_{4}+I_{7}
\end{array}\right]
$$

\subsubsection{Network Partition II}

Another way of partitioning the network is presented in this section, where the network is divided into eight sections as shown in Figure 4. 


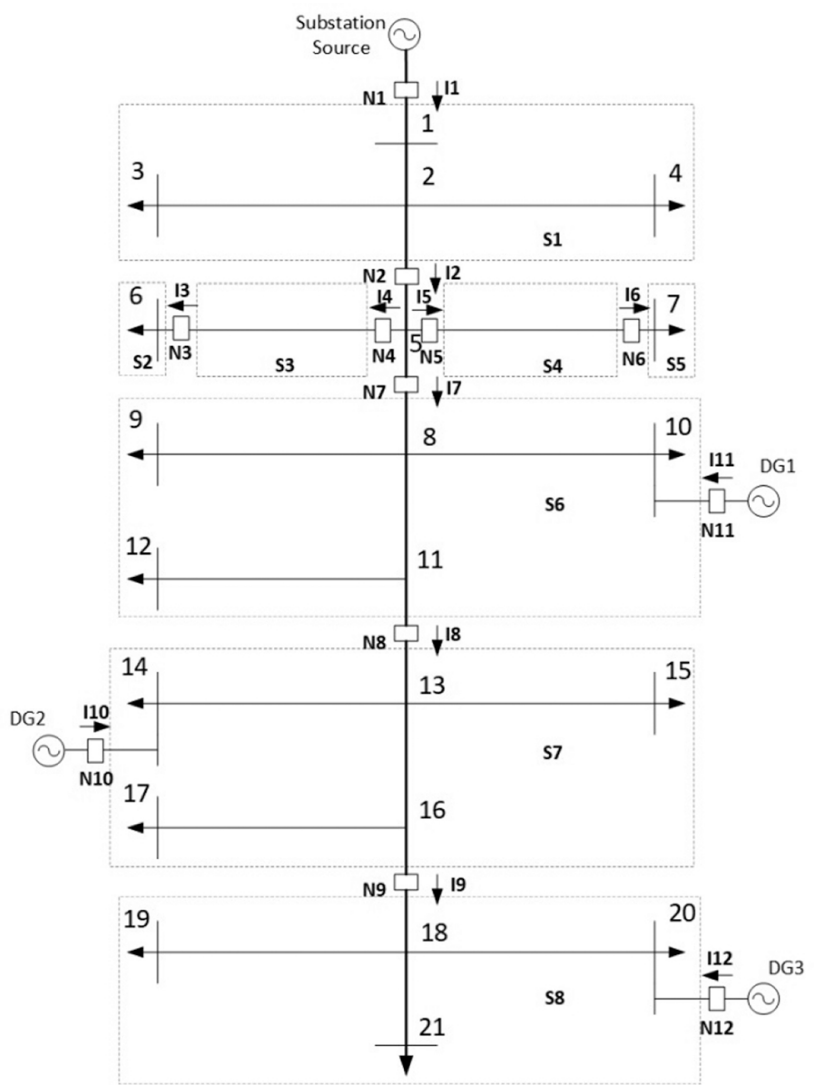

Figure 4: A 21-bus system being divided into eight sections.

The connection matrix $N$ of Figure 4 is shown below:

$$
N=\left[\begin{array}{cccccccccccc}
1 & -1 & 0 & 0 & 0 & 0 & 0 & 0 & 0 & 0 & 0 & 0 \\
0 & 0 & 1 & 0 & 0 & 0 & 0 & 0 & 0 & 0 & 0 & 0 \\
0 & 0 & -1 & 1 & 0 & 0 & 0 & 0 & 0 & 0 & 0 & 0 \\
0 & 0 & 0 & 0 & 1 & -1 & 0 & 0 & 0 & 0 & 0 & 0 \\
0 & 0 & 0 & 0 & 0 & 1 & 0 & 0 & 0 & 0 & 0 & 0 \\
0 & 0 & 0 & 0 & 0 & 0 & 1 & -1 & 0 & 0 & 1 & 0 \\
0 & 0 & 0 & 0 & 0 & 0 & 0 & 1 & -1 & 1 & 0 & 0 \\
0 & 0 & 0 & 0 & 0 & 0 & 0 & 0 & 1 & 0 & 0 & 1
\end{array}\right]
$$

The current vector is

$$
I=\left[\begin{array}{lllllll}
I_{1} & I_{2} & I_{3} & I_{4} & I_{5} & I_{6} & I_{7} I_{8} I_{9} I_{11} I_{12}
\end{array}\right]^{T},
$$

where subscript $T$ denotes transpose. The currents are labeled in Figure 4 .

By using (12), the fault section identification vectors are obtained as

$$
F_{S}=\left[\begin{array}{c}
I_{1}-I_{2} \\
I_{3} \\
-I_{3}+I_{4} \\
I_{5}-I_{6} \\
I_{6} \\
I_{7}-I_{8}+I_{11} \\
I_{8}-I_{9}+I_{10} \\
I_{9}+I_{12}
\end{array}\right]
$$

It is evident that the more areas into which the network is partitioned, the finer resolution the fault section identification result will have. 


\section{Proposed Fault Location Method}

Once the faulted sections are identified, accurate fault location will be calculated using the method described in this section. The method to be presented is generic and is applicable to single or multiple faults.

Figure 5 illustrates a multiple fault scenario, where two faults occur at fault points $F_{1}$ and $F_{2}$ on feeder $P_{1} Q_{1}$ and $P_{2} Q_{2}$, respectively [10].
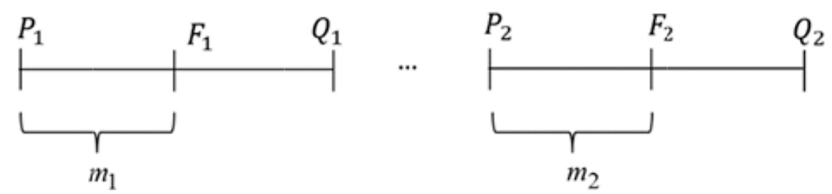

Figure 5: Illustration of multiple faults.

The current injections to the network include the line currents at the sources and the fault currents. Therefore, the voltage during the fault at any bus $l$ can be written as

$$
E_{l}=Z_{l K} I_{K}-Z_{l F_{1}} I_{F_{1}}-Z_{l F_{2}} I_{F_{2}}
$$

or

$$
E_{l}=Z_{l K} I_{K}-\left[\begin{array}{ll}
Z_{l F_{1}} & Z_{l F_{2}}
\end{array}\right]\left[\begin{array}{ll}
I_{F_{1}} & I_{F_{2}}
\end{array}\right]^{T}
$$

Now assume that the voltages at buses $L_{1}$ and $L_{2}$ are known. The following two equations are obtained:

$$
\begin{aligned}
& E_{L_{1}}=Z_{L_{1} K} I_{K}-\left[\begin{array}{ll}
Z_{L_{1} F_{1}} & Z_{L_{1} F_{2}}
\end{array}\right]\left[\begin{array}{ll}
I_{F_{1}} & I_{F_{2}}
\end{array}\right]^{T} \\
& E_{L_{2}}=Z_{L_{2} K} I_{K}-\left[\begin{array}{ll}
Z_{L_{2} F_{1}} & Z_{L_{2} F_{2}}
\end{array}\right]\left[\begin{array}{ll}
I_{F_{1}} & I_{F_{2}}
\end{array}\right]^{T}
\end{aligned}
$$

or in a compact format,

$$
\left[\begin{array}{c}
E_{L_{1}} \\
E_{L_{2}}
\end{array}\right]=\left[\begin{array}{c}
Z_{L_{1} K} \\
Z_{L_{2} K}
\end{array}\right] I_{K}-\left[\begin{array}{cc}
Z_{L_{1} F_{1}} & Z_{L_{1} F_{2}} \\
Z_{L_{2} F_{1}} & Z_{L_{2} F_{2}}
\end{array}\right]\left[\begin{array}{c}
I_{F_{1}} \\
I_{F_{2}}
\end{array}\right]
$$

where,

$E_{L_{1}}, E_{L_{2}}$ : the voltage during the fault at bus $L_{1}, L_{2}$, respectively;

$K$ : source buses;

$Z_{L_{1} K}, Z_{L_{2} K}$ : transfer impedance matrix between bus $L_{1}$ and $K$, bus $L_{2}$ and $K$, respectively;

$Z_{L_{1} F_{1}}, Z_{L_{1} F_{2}}$ : transfer impedance matrix between bus $L_{1}$ and $F_{1}$, bus $L_{1}$ and $F_{2}$, respectively;

$Z_{L_{2} F_{1}}, Z_{L_{2} F_{2}}$ : transfer impedance matrix between bus $L_{2}$ and $F_{1}$, bus $L_{2}$ and $F_{2}$, respectively;

$I_{F_{1}}, I_{F_{2}}$ : the fault currents at point $F_{1}$ and $F_{2}$.

Equation (24) can be written in a more compact form as follows:

$$
E_{L_{1} L_{2}}=Z_{L_{1} L_{2} K} I_{K}-Z_{L_{1} L_{2} F_{1} F_{2}} I_{F_{1} F_{2}}
$$

The fault current vector is obtained as

$$
\begin{gathered}
I_{F_{1} F_{2}}= \\
\left(Z_{L_{1} L_{2} F_{1} F_{2}}^{T} Z_{L_{1} L_{2} F_{1} F_{2}}\right)^{-1}\left[Z_{L_{1} L_{2} F_{1} F_{2}}^{T}\left(Z_{L_{1} L_{2} K} I_{K}-E_{L_{1} L_{2}}\right)\right]
\end{gathered}
$$

The voltages at the fault points are expressed as

$$
E_{F_{1} F_{2}}=Z_{F_{1} F_{2} K} I_{K}-Z_{F_{1} F_{2} F_{1} F_{2}} I_{F_{1} F_{2}}
$$


Since the fault resistances only consume real power, the imaginary part of the complex power consumed by the fault resistance is zero,

$$
\begin{aligned}
& \operatorname{Imag}\left(E_{F_{1}}^{T} I_{F_{1}}^{*}\right)=0 \\
& \operatorname{Imag}\left(E_{F_{2}}^{T} I_{F_{2}}^{*}\right)=0
\end{aligned}
$$

where Imag(.) yields the imaginary part of its argument.

Then, the two unknown fault locations can be determined by solving this set of real equations.

The derivation indicates that voltage measurements from any bus can be utilized for the fault location algorithm. But it is natural to use the voltages at the source buses since meters are required to record source currents at source locations.

Note that this method can be applied to both a meshed network and a radial network that contains only one source at the local substation.

\section{Evaluation Studies}

This section presents the evaluation studies for verifying the effectiveness of the proposed methods. Matlab [11] has been utilized to simulate different fault sections, types, locations, and fault resistances. A 21-bus distribution system is utilized for evaluation studies, which is shown in Figure 2.

Case studies of the fault section identification algorithm are demonstrated in Section 4.1, with multiple scenarios including single fault and multiple simultaneous faults. After fault sections have been identified, then the proposed fault location algorithm can be applied to pinpoint the fault location. Studies of fault location algorithm are shown in Section 4.2. The estimation accuracy is measured by the percentage error obtained as

$$
\% \text { Error }=\frac{\mid \text { Actual location }- \text { Estimated location } \mid}{\text { Total length of the main feeder }} \times 100 \%
$$

For section 4.1, measurements from edges of fault sections are utilized. Measurement from meters placed at bus 1,14 and 20 are used for section 4.2. In the study, an estimation error of $0.2 \%$ is utilized for all measurements to make the case studies closer to real practices.

\subsection{Fault Section Identification}

This section presents the evaluation studies for the developed fault section identification algorithm.

\subsubsection{Network Partition I}

This part presents the fault section identification results of network partition I. Cases with different fault sections and fault types are studied.

The pre-fault fault section identification vectors are listed in Table 1 . In the table, columns 1 list the section numbers. The fault section identification vectors of phase A, B, and C are listed in columns 2-4, respectively. The identification vectors shown in Table 1 are mainly due to load currents.

Table 1: Fault section identification vectors of network partition I preceding the fault.

\begin{tabular}{llll}
\hline Section Number & $F_{S_{a}}$ & $F_{S_{b}}$ & $F_{S_{c}}$ \\
\hline 1 & 39.018 & 49.258 & 37.673 \\
2 & 32.172 & 29.104 & 14.931 \\
3 & 23.970 & 23.826 & 36.711 \\
4 & 33.433 & 33.272 & 33.251 \\
\hline
\end{tabular}


For the single fault study, a phase A to ground fault is imposed in section 1 on the line between bus 2 and bus 5 . The results are listed in Table 2 . Phases with abnormal vector values are listed in column 5.

Table 2: Fault section identification vectors of network partition I for a single fault.

\begin{tabular}{lllll}
\hline Section Number & $F_{S_{a}}$ & $F_{S_{b}}$ & $F_{S_{c}}$ & Abnormal Phase \\
\hline 1 & 942.853 & 50.224 & 39.830 & Phase A \\
2 & 24.848 & 29.547 & 15.537 & No \\
3 & 20.751 & 24.004 & 37.169 & No \\
4 & 29.515 & 33.339 & 33.514 & No \\
\hline
\end{tabular}

It is observed that the fault section identification vector of section 1 is significantly larger than pre-fault values. This observation indicates that a fault occurs in section 1. Moreover, phase A is the only abnormal phase, and thus the fault is determined as a phase A to ground fault. To facilitate identification faulted phases, the following process is used.

Let $F_{s_{p r e}}$ denote the fault identification vectors preceding the fault, and $F_{s}$ denote the fault identification vectors during the fault. Table 3 lists the absolute value of the difference between the magnitude of $F_{s_{p r e}}$ and the magnitude of $F_{S}$. Table 4 lists the magnitude of the difference between $F_{s_{p r e}}$ and $F_{s}$. Since $F_{s}$ and $F_{s_{p r e}}$ are phasors, Table 3 and Table 4 are different. It is clearly evinced from Table 3 and Table 4 that there is a significant increase in phase A identification index for section 1, so it is concluded that a phase A to ground fault occurs in Section 1.

Table 3: $\left|\left(\left|F_{s}\right|-\left|F_{s p r e}\right|\right)\right|$ of network partition I for a single fault.

\begin{tabular}{lllll}
\hline Section Number & $\left|\Delta F_{S_{a}}\right|$ & $\left|\Delta F_{S_{b}}\right|$ & $\left|\Delta F_{S_{c}}\right|$ & Abnormal Phase \\
\hline 1 & 903.835 & 0.966 & 2.157 & Phase A \\
2 & 7.324 & 0.443 & 0.606 & No \\
3 & 3.219 & 0.178 & 0.458 & No \\
4 & 3.918 & 0.067 & 0.263 & No \\
\hline
\end{tabular}

Table 4: $\left|\left(F_{s}-F_{s p r e}\right)\right|$ of network partition I for a single fault.

\begin{tabular}{lllll}
\hline Section Number & $\left|\Delta F_{S_{a}}\right|$ & $\left|\Delta F_{S_{b}}\right|$ & $\left|\Delta F_{S_{c}}\right|$ & Abnormal Phase \\
\hline 1 & 903.871 & 3.698 & 2.641 & Phase A \\
2 & 11.460 & 1.802 & 0.728 & No \\
3 & 6.831 & 0.388 & 0.580 & No \\
4 & 8.805 & 0.277 & 0.287 & No \\
\hline
\end{tabular}

For multiple simultaneous faults, two faults are imposed in the study. One fault is phase $\mathrm{C}$ to ground fault, which is imposed in section 2 on the line between bus 9 and 11. The other fault is a three-phase fault, imposed on section 4 on the line between bus 18 and 20. The results are presented in Table 5. The absolute value of the difference between the magnitude of $F_{s_{\text {pre }}}$ and the magnitude of $F_{s}$ is listed in Table 6. The magnitude of the difference between $F_{s_{\text {pre }}}$ and $F_{s}$ is listed in Table 7.

Table 5: Fault section identification vectors of network partition I for multiple faults.

\begin{tabular}{lllll}
\hline Section Number & $F_{S_{a}}$ & $F_{S_{b}}$ & $F_{S_{c}}$ & Abnormal Phase \\
\hline 1 & 32.713 & 38.443 & 18.028 & No \\
2 & 23.035 & 19.024 & 772.877 & Phase C \\
3 & 14.194 & 10.465 & 7.761 & No \\
4 & 870.770 & 985.571 & 744.613 & Phase A, B, and C \\
\hline
\end{tabular}


Table 6: $\left|\left(\left|F_{s}\right|-\left|F_{s_{\text {pre }}}\right|\right)\right|$ of network partition I for multiple faults.

\begin{tabular}{lllll}
\hline Section Number & $\left|\Delta F_{S_{a}}\right|$ & $\left|\Delta F_{S_{b}}\right|$ & $\left|\Delta F_{S_{c}}\right|$ & Abnormal Phase \\
\hline 1 & 6.305 & 10.815 & 19.645 & No \\
2 & 9.137 & 10.080 & 757.946 & Phase C \\
3 & 9.776 & 13.361 & 28.950 & No \\
4 & 837.337 & 952.299 & 711.362 & Phase A, B, and C \\
\hline
\end{tabular}

Table 7: $\left|\left(F_{s}-F_{\text {spre }}\right)\right|$ of network partition I for multiple faults.

\begin{tabular}{lllll}
\hline Section Number & $\left|\Delta F_{S_{a}}\right|$ & $\left|\Delta F_{S_{b}}\right|$ & $\left|\Delta F_{S_{c}}\right|$ & Abnormal Phase \\
\hline 1 & 9.447 & 11.705 & 21.490 & No \\
2 & 12.950 & 10.110 & 761.473 & Phase C \\
3 & 12.083 & 13.502 & 34.361 & No \\
4 & 842.564 & 962.161 & 722.380 & Phase A, B, and C \\
\hline
\end{tabular}

Based on results listed in Table 5-Table 7, it can be determined that there is a phase $C$ to ground fault in section 2 and a three-phase fault in section 4. This result is accurate. Again, it shows that the change in identification vector is a more pronounced indicator than the identification vector during the fault. So, it is preferred to use either $\left|\left(\left|F_{s}\right|-\left|F_{s_{p r e}}\right|\right)\right|$ or $\left|\left(F_{s}-F_{s_{p r e}}\right)\right|$ to decide faulted types and sections.

It is evinced that the proposed fault section identification method yields not only accurate fault sections but also fault types. It can be inferred that even with possible current measurement error, say $2 \%$ error, the proposed indicator will still yield correct faulted sections and types. For example, examine second row of Table 7. Even with possible current measurements, $\left|\Delta F_{S_{c}}\right|$ will still be significantly larger than the values for phase a and $b$, thus clearly indicating phase $C$ fault.

\subsubsection{Network Partition II}

In this part, fault section identification results of network partition II are presented. Various fault conditions have been studied.

The pre-fault fault section identification vectors are listed in Table 8. It is noted that all vectors listed are small, which reflects the load currents and indicates there is no fault in the system. Note that the values of $F_{S_{a}}$ of section 2 and 3 are zero. The reason is that the line from bus 5 to 6 has phase B and C only.

Table 8: Fault section identification vectors of network partition II preceding the fault.

\begin{tabular}{llll}
\hline Section Number & $F_{S_{a}}$ & $F_{S_{b}}$ & $F_{S_{c}}$ \\
\hline 1 & 30.353 & 30.185 & 18.665 \\
2 & 0 & 21.333 & 11.632 \\
3 & 0 & 22.522 & 21.224 \\
4 & 2.621 & 19.823 & 18.460 \\
5 & 9.192 & 18.633 & 10.175 \\
6 & 32.172 & 29.104 & 14.931 \\
7 & 23.970 & 23.826 & 36.711 \\
8 & 33.433 & 33.272 & 33.251 \\
\hline
\end{tabular}

For single fault study, a phase B to ground fault in section 1 on the line between bus 2 and 4 is imposed. The simulation results are listed in Table 9. Table 10 lists the absolute value of the difference between the magnitude of $F_{s_{\text {pre }}}$ and the magnitude of $F_{s}$. The magnitude of the difference between $F_{s_{\text {pre }}}$ and the $F_{s}$ is listed in Table 11. 
Table 9: Fault section identification vectors of network partition II for a single fault.

\begin{tabular}{lllll}
\hline Section Number & $F_{S_{a}}$ & $F_{S_{b}}$ & $F_{S_{c}}$ & Abnormal Phase \\
\hline 1 & 34.040 & 1315.233 & 18.925 & Phase B \\
2 & 0 & 21.333 & 11.632 & No \\
3 & 0 & 19.562 & 21.335 & No \\
4 & 2.638 & 17.177 & 18.567 & No \\
5 & 9.192 & 18.633 & 10.175 & No \\
6 & 33.937 & 17.836 & 14.747 & No \\
7 & 24.208 & 17.988 & 36.364 & No \\
8 & 33.597 & 25.941 & 32.842 & No \\
\hline
\end{tabular}

Table 10: $\left|\left(\left|F_{s}\right|-\left|F_{s_{p r e}}\right|\right)\right|$ of network partition II for a single fault.

\begin{tabular}{lllll}
\hline Section Number & $\left|\Delta F_{S_{a}}\right|$ & $\left|\Delta F_{S_{b}}\right|$ & $\left|\Delta F_{S_{c}}\right|$ & Abnormal Phase \\
\hline 1 & 3.687 & 1285.048 & 0.260 & Phase B \\
2 & 0 & 0.000 & 0.000 & No \\
3 & 0 & 2.960 & 0.111 & No \\
4 & 0.017 & 2.646 & 0.107 & No \\
5 & 0.000 & 0.000 & 0.000 & No \\
6 & 1.765 & 11.268 & 0.184 & No \\
7 & 0.238 & 5.838 & 0.347 & No \\
8 & 0.164 & 7.331 & 0.409 & No \\
\hline
\end{tabular}

Table 11: $\left|\left(F_{s}-F_{s_{p r e}}\right)\right|$ of network partition II for a single fault.

\begin{tabular}{lllll}
\hline Section Number & $\left|\Delta F_{S_{a}}\right|$ & $\left|\Delta F_{S_{b}}\right|$ & $\left|\Delta F_{S_{c}}\right|$ & Abnormal Phase \\
\hline 1 & 4.431 & 1285.821 & 1.943 & Phase B \\
2 & 0 & 0.000 & 0.000 & No \\
3 & 0 & 5.421 & 1.024 & No \\
4 & 0.809 & 4.718 & 0.890 & No \\
5 & 0.000 & 0.000 & 0.000 & No \\
6 & 1.879 & 13.306 & 0.889 & No \\
7 & 0.241 & 8.635 & 0.712 & No \\
8 & 0.341 & 11.184 & 0.477 & No \\
\hline
\end{tabular}

It is seen that $F_{S_{b}}$ of section 1 is significantly larger than the pre-fault value, which indicates a phase B to ground fault occurs in section 1 .

For multiple simultaneous fault study, two faults are imposed. A three-phase fault is imposed on the line between bus 8 and 11 in section 6 . The second fault is imposed in section 7 on the line from bus 13 to 16 .

Table 12, Table 13 and Table 14 present the results of studies. The fault section identification vectors indicate that there is a three-phase fault in section 6 and a phase B and C to ground fault in section 7.

Table 12: Fault section identification vectors of network partition II for multiple faults.

\begin{tabular}{lllll}
\hline Section Number & $F_{S_{a}}$ & $F_{S_{b}}$ & $F_{S_{c}}$ & Abnormal Phases \\
\hline 1 & 19.997 & 17.049 & 11.230 & No \\
2 & 0 & 33.832 & 32.600 & No \\
3 & 0 & 32.321 & 36.309 & No \\
4 & 19.743 & 28.316 & 31.743 & No \\
5 & 21.374 & 29.580 & 28.510 & No \\
6 & 1477.006 & 1141.096 & 1102.220 & Phase A, B, and C \\
7 & 10.170 & 569.221 & 567.888 & Phase B, and C \\
8 & 15.250 & 8.721 & 7.021 & No \\
\hline
\end{tabular}


Table 13: $\mathrm{I}\left|\left(\left|F_{s}\right|-\left|F_{s_{p r e}}\right|\right)\right|$ of network partition II for multiple faults.

\begin{tabular}{lllll}
\hline Section Number & $\left|\Delta F_{S_{a}}\right|$ & $\left|\Delta F_{S_{b}}\right|$ & $\left|\Delta F_{S_{c}}\right|$ & Abnormal Phases \\
\hline 1 & 10.356 & 13.136 & 7.435 & No \\
2 & 0 & 12.499 & 20.968 & No \\
3 & 0 & 9.799 & 15.085 & No \\
4 & 17.122 & 8.493 & 13.283 & No \\
5 & 12.182 & 10.947 & 18.335 & No \\
6 & 1444.834 & 1111.992 & 1087.289 & Phase A, B, and C \\
7 & 13.800 & 545.395 & 531.177 & Phase B, and C \\
8 & 18.183 & 24.551 & 26.230 & No \\
\hline
\end{tabular}

Table 14: $\left|\left(F_{s}-F_{s_{p r e}}\right)\right|$ of network partition II for multiple faults.

\begin{tabular}{lllll}
\hline Section Number & $\left|\Delta F_{S_{a}}\right|$ & $\left|\Delta F_{S_{b}}\right|$ & $\left|\Delta F_{S_{c}}\right|$ & Abnormal Phases \\
\hline 1 & 13.017 & 15.150 & 8.881 & No \\
2 & 0 & 12.509 & 21.691 & No \\
3 & 0 & 14.566 & 15.086 & No \\
4 & 18.113 & 12.637 & 13.289 & No \\
5 & 13.472 & 10.956 & 18.966 & No \\
6 & 1451.063 & 1122.010 & 1089.271 & Phase A, B, and C \\
7 & 16.517 & 548.908 & 567.369 & Phase B, and C \\
8 & 21.704 & 31.166 & 26.763 & No \\
\hline
\end{tabular}

It is shown that accurate fault sections and fault types have been achieved by the developed fault section identification algorithm.

\subsection{Fault Location}

This section evaluates the performance of the developed fault location algorithms. Studies of different fault types, locations, and resistances have been performed, and results are presented.

The proposed methods have yielded quite accurate results for different fault conditions, as shown in Table 15 , where actual fault conditions are listed in columns 1-5, and estimated fault location errors are provided in the last column.

Table 15: Fault location results using voltages from bus 1, bus 14, and bus 20 .

\begin{tabular}{llllll}
\hline Case type & Fault number & $\begin{array}{l}\text { Fault section, and } \\
\text { fault type }\end{array}$ & FL (p.u.) & Fault res. (ohm) & $\begin{array}{l}\text { FL Esti. } \\
\text { err. (\%) }\end{array}$ \\
\hline Single fault & Fault 1 & $(1-2, \mathrm{ABG})$ & 0.5 & {$[1,1,10]$} & 0.01 \\
Single fault & Fault 1 & $(2-5, \mathrm{ABC})$ & 0.4 & {$[1,1,1]$} & 0.03 \\
Single fault & Fault 1 & $(8-10, \mathrm{AG})$ & 0.7 & {$[1,50]$} & 0.02 \\
Single fault & Fault 1 & $(16-18, \mathrm{ABCG})$ & 0.9 & {$[1,1,110]$} & 0.18 \\
Single fault & Fault 1 & $(18-21, \mathrm{BG})$ & 0.3 & {$[5,50]$} & 0.07 \\
Multiple faults & Fault 1 & $(1-2, \mathrm{BG})$ & 0.4 & {$[1,5]$} & 0.01 \\
& Fault 2 & $(18-19, \mathrm{CG})$ & 0.2 & {$[1,10]$} & 0.14 \\
Multiple faults & Fault 1 & $(1-2, \mathrm{AG})$ & 0.5 & {$[1,10]$} & 0.03 \\
& Fault 2 & $(5-8, \mathrm{ABC})$ & 0.3 & {$[1,1,1]$} & 0.01 \\
Multiple faults & Fault 1 & $(2-5, \mathrm{AG})$ & 0.4 & {$[1,5]$} & 0.02 \\
& Fault 2 & $(18-21, \mathrm{BCG})$ & 0.7 & {$[0.5,0.5,5]$} & 0.06 \\
Multiple faults & Fault 1 & $(2-5, \mathrm{CG})$ & 0.5 & {$[1,10]$} & 0.05 \\
& Fault 2 & $(13-15, \mathrm{ABC})$ & 0.8 & {$[1,1,1]$} & 0.03 \\
Multiple faults & Fault 1 & $(1-2, \mathrm{AG})$ & 0.2 & {$[1,10]$} & 0.01 \\
& Fault 2 & $(13-16, \mathrm{ABCG})$ & 0.5 & {$[1,1,1,5]$} & 0.01 \\
\hline
\end{tabular}


It is worth pointing out that voltage measurements from one bus will be sufficient to locate single faults. Take voltage measurement from bus 1 as an example, the fault locations of first five cases listed in Table 15 can be obtained, and the estimation errors are $0.02 \%, 0.02 \%, 0.05 \%, 0.14 \%$ and $0.16 \%$, respectively.

Table 16 presents the fault location results for cases involving three simultaneous faults using voltages from buses 1,14 and 20. It is shown that highly accurate results are achieved by the proposed methods.

Table 16: Fault location results for three simultaneous faults.

\begin{tabular}{llllll}
\hline Case type & $\begin{array}{l}\text { Fault } \\
\text { number }\end{array}$ & $\begin{array}{l}\text { Fault section, and } \\
\text { fault type }\end{array}$ & FL (p.u.) & Fault res. (ohm) & $\begin{array}{l}\text { FL Esti. } \\
\text { err. (\%) }\end{array}$ \\
\hline \multirow{2}{*}{ Multiple faults } & Fault 1 & $(1-2, \mathrm{BG})$ & 0.5 & {$[5,10]$} & 0.27 \\
& Fault 2 & $(5-6, \mathrm{CG})$ & 0.6 & {$[1,10]$} & 0.22 \\
& Fault 3 & $(8-11, \mathrm{AG})$ & 0.5 & {$[1,5]$} & 0.01 \\
Multiple faults & Fault 1 & $(1-2, \mathrm{ABC})$ & 0.8 & {$[1,1,1]$} & 0.01 \\
& Fault 2 & $(8-11, \mathrm{BG})$ & 0.3 & {$[1,25]$} & 0.37 \\
& Fault 3 & $(13-16, \mathrm{BC})$ & 0.4 & {$[1,1]$} & 0.01 \\
Multiple faults & Fault 1 & $(2-5, \mathrm{ABCG})$ & 0.1 & {$[1,1,120]$} & 0.01 \\
& Fault 2 & $(5-8, \mathrm{BG})$ & 0.4 & {$[1,25]$} & 0.33 \\
& Fault 3 & $(18-20, \mathrm{AG})$ & 0.4 & {$[0.5,10]$} & 0.00 \\
Multiple faults & Fault 1 & $(5-7, \mathrm{AG})$ & 0.8 & {$[1,5]$} & 0.44 \\
& Fault 2 & $(11-12, \mathrm{BCG})$ & 0.9 & {$[1,1,10]$} & 0.03 \\
& Fault 3 & $(16-18, \mathrm{ABC})$ & 0.9 & {$[1,1,1]$} & 0.05 \\
Multiple faults & Fault 1 & $(1-2, \mathrm{ABC})$ & 0.5 & {$[0.5,0.5,0.5]$} & 0.01 \\
& Fault 2 & $(5-6, \mathrm{CG})$ & 0.8 & {$[5,15]$} & 0.46 \\
& Fault 3 & $(13-15, \mathrm{AG})$ & 0.7 & {$[1,25]$} & 0.02 \\
\hline
\end{tabular}

\section{Conclusion}

This paper presents a novel graph-based method for identifying fault section in distribution network using current measurements. A fault location method applicable for simultaneous, multiple faults is also proposed. The proposed methods are applicable to power grid with distributed generations and with unbalances.

Evaluation studies have demonstrated highly accurate results have been obtained by the proposed fault section identification and location methods. The methods will speed up locating faulted component, and thus expedite the repair and restoration process and reduce outage time.

\section{References}

[1] Saha MM, Izykowski ], Rosolowski E. Fault location on power networks. London: Springer-Verlag London Ltd; 2010.

[2] Chaderi A, Mohammadpour HA, Ginn H, "Active fault location in distribution network using time-frequency reflectometry," 2015 IEEE Power and Energy Conference at Illinois (PECI), Champaign, IL, pp. 1-7, 2015.

[3] Jiang Y, Liu CC, Diedesch M, Lee E, Srivastava AK. Outage management of distribution systems incorporating information from smart meters. IEEE Trans Power Syst. 2016;31(5):4144-54.

[4] Coudarzi M, Vahidi B, Naghizadeh RA, Hosseinian SH. Improved fault location algorithm for radial distribution systems with discrete and continuous wavelet analysis. Int ] Electrical Power Energy Syst. 2015;67:423 .

[5] Cazzana DS, Ferreira CD, Bretas AS, Bettiol AL, Carniato A, Passos LFN, et al. An integrated technique for fault location and section identification in distribution systems. Electric Power Syst Res. 2014;115:65 .

[6] Ning Kang M], Mousavi MZ. Faulted segment identification in multi-phase distribution systems using sequence component modeling. Electric Power Components Syst. 2015;44:1

[7] Majidi M, Etezadi-Amoli M, Sami Fadali M. A novel method for single and simultaneous fault location in distribution networks. IEEE Transactions on Power Systems. 2015;30(6):3368-3376.

[8] Liao Y. A novel fault location method for radial distribution systems. Int ] Emerging Electric Power Syst. 2015;16(3):225-232 .

[9] Xiu W, Liao Y. Fault location observability analysis on power distribution systems. Electric Power Components Syst. 2014;42(16):1862-71 .

[10] Fan W, Liao Y. Fault location techniques for simultaneous faults in power distribution systems with distributed generations. 2017 International Energy and Sustainability Conference (IESC). Farmingdale, NY, USA; 2017;1-8.

[11] MATLAB Release. The mathworks, inc. Natick, Massachusetts: United States; $2016 \mathrm{~b}$. 